\title{
How do physician demographics, training, social media usage, online presence, and wait times influence online physician review scores for spine surgeons?
}

\author{
Chester J. Donnally III, MD, ${ }^{1}$ Johnathon R. McCormick, BS, ${ }^{2}$ Deborah J. Li, BA, ${ }^{2}$ \\ James A. Maguire Jr., BS, ${ }^{2}$ Grant P. Barker, BS, ${ }^{2}$ Augustus J. Rush III, MD, ${ }^{1}$ and \\ Michael Y. Wang, MD
}

${ }^{1}$ Department of Orthopaedic Surgery, University of Miami Hospital; and Departments of ${ }^{2}$ Education and ${ }^{3}$ Neurological Surgery, University of Miami Leonard M. Miller School of Medicine, Miami, Florida

\begin{abstract}
OBJECTIVE The purpose of this study was to assess the impact of certain demographics, social media usage, and physician review website variables for spine surgeons across Healthgrades.com (Healthgrades), Vitals.com (Vitals), and Google.com (Google).

METHODS Through a directory of registered North American Spine Society (NASS) physicians, we identified spine surgeons practicing in Texas (107 neurosurgery trained, 192 orthopedic trained). Three physician rating websites (Healthgrades, Vitals, Google) were accessed to obtain surgeon demographics, training history, practice setting, number of ratings/reviews, and overall score (January 2, 2018-January 16, 2018). Using only the first 10 search results from Google.com, we then identified whether the surgeon had a website presence or an accessible social media account on Facebook, Twitter, and/or Instagram.
\end{abstract}

RESULTS Physicians with either a personal or institutional website had a higher overall rating on Healthgrades compared to those who did not have a website $(p<0.01)$. Nearly all spine surgeons had a personal or institutional website $(90.3 \%)$, and at least 1 accessible social media account was recorded for $43.5 \%$ of the spine surgeons in our study cohort (39.5\% Facebook, 10.4\% Twitter, 2.7\% Instagram). Social media presence was not significantly associated with overall ratings across all 3 sites, but it did significantly correlate with more comments on Healthgrades. In multivariable analysis, increasing surgeon age was significantly associated with a lower overall rating across all 3 review sites $(p<$ $0.05)$. Neurosurgeons had higher overall ratings on Vitals $(p=0.04)$. Longer wait times were significantly associated with a lower overall rating on Healthgrades $(p<0.0001)$. Overall ratings from all 3 websites correlated significantly with each other, indicating agreement between physician ratings across different platforms.

CONCLUSIONS Longer wait times, increasing physician age, and the absence of a website are indicative of lower online review scores for spine surgeons. Neurosurgery training correlated with a higher overall review score on Vitals. Having an accessible social media account does not appear to influence scores, but it is correlated with increased patient feedback on Healthgrades. Identification of ways to optimize patients' perception of care are important in the future of performance-based medicine.

https://thejns.org/doi/abs/10.3171/2018.8.SPINE18553

KEYWORDS social media; online patient ratings; physician review websites; spine surgeon ratings; wait times; Google; Healthgrades; Vitals

$\mathrm{R}$ ECENT trends in medicine have shown a movement toward a physician reimbursement system that is focused on quality over quantity of service..$^{13}$ Identification and optimization of variables that promote patient satisfaction continue to increase in importance. Similarly, physicians are more aware of the importance of reputation and marketing to advertise their services. A rapidly in- creasing method of identifying and evaluating healthcare providers is the use of online physician review websites. ${ }^{8}$ Among a cohort of patients seeking a care provider who utilize online review sites, $35 \%$ chose a physician based on "good" ratings and $37 \%$ avoided a physician based on "bad" ratings. ${ }^{8}$ Despite no correlation to patient outcome or physician performance, patients are influenced by non- 
regulated review sites. In a study of 752 orthopedic patients by Curry et al., $18 \%-26 \%$ of new patients used a physician review website before their consultation. ${ }^{3}$ It is clear that patients are placing an increased value on physician review sites, and potentially reimbursement modalities may follow in the near future. Within this ever-changing landscape, it is important for physicians to promote a positive online appearance.

To study the effect of social media on orthopedic surgery, Duymus et al. conducted a survey of 321 orthopedic surgeons and reported that $73 \%$ of those surveyed had Facebook accounts. ${ }^{6}$ Of those, $83 \%$ reported being contacted by patients on social media. In a separate survey of orthopedic patients, $34 \%$ reported online consultations with an orthopedic surgeon, and 39\% said the Internet had an effect on their choice of physician. ${ }^{5}$ Almost half of these patients also reported their orthopedic surgeon should keep in contact with them using the Internet. As of September 2017, the numbers of active Facebook, Twitter, and Instagram users were 2.06 billion, 328 million, and 700 million, respectively (https://www.statista.com/statistics/272014/ global-social-networks-ranked-by-number-of-users/). The staggering numbers of people using social media, coupled with patients' desires to keep in contact with their physician, are making online physician profiles more important.

The purpose of this study was to evaluate various factors associated with patient engagement (measured by the frequency of reviews and comments) and patient satisfaction (measured by overall scores). A secondary aim was to determine whether spine surgeons with a social media presence had a difference in the frequency of online ratings, or scores, compared to those without a social media presence. We hypothesize that those surgeons with a public social media presence will have higher profile scores, more comments, and more total reviews and are more likely orthopedic trained in private practice. To date this is the largest reviewed cohort of spine surgeons (299), and one of the only to include Google.com as an online physician review source.

\section{Methods \\ Data Collection}

Using the online "Find a Specialist" function in the member directory for the North American Spine Society (NASS), we identified all members practicing in Texas identifying as either orthopedic surgeons or neurosurgeons. This search yielded a total of of 355 spine surgeons (based on December 20, 2017, access of the directory). Review determined that 28 were still in training (resident/ fellow), 16 practiced outside of Texas, 7 were not actually surgeons, and 5 had retired; these individuals were excluded, leaving a total of 299 surgeons in the study cohort. Using our 3 online review sites, we confirmed that each of these physicians had completed orthopedic or neurosurgery residency and was an active spine surgeon.

We then reviewed profiles for individual surgeons, using 3 of the more highly rated physician review websites: Healthgrades.com (Healthgrades), Vitals.com (Vitals), and Google.com (Google) (accessed from 1/02/2018 to $1 / 16 / 2018)$. These sites were previously recommended by the reputation industry at rates of $88 \%, 94 \%$, and $100 \%$, respectively. ${ }^{2}$ We used all 3 sites to confirm information on residency training type (orthopedic surgery vs neurosurgery), degree (medical doctorate [MD] vs doctor of osteopathic medicine [DO]), graduation year, practice zip code, and institution setting (academic vs private). From Healthgrades, we recorded age, presence of a "care philosophy" (i.e., personal profile established by the surgeon on Healthgrades), the patient-reported wait time $(<10,10-15$, 16-30, or 30+ minutes), number of ratings, and overall rating (out of 5). From Vitals we recorded: years of experience, Castle Connolly status (i.e., Vitals' specific award for their top doctors based on multiple factors), number of ratings, number of comments, and overall rating (out of 5). From Google we recorded: total reviews, comments, and overall rating (out of 5).

We searched each NASS spine surgeon on Google.com ("first name" + "last name" + "MD" + "spine") and reviewed the first 10 search results for the surgeon's website (institutional vs personal). We did not also search "DO" because: 1) patients usually do not know or search this difference in degrees; 2) "DO" is seen as the word "do" in a Google search, skewing results; 3 ) "MD" is equivalent for "doctor" in this context and it seems likely that a patient would also search "MD" or "doctor." To evaluate social media presence, we added our 3 social media platforms to the initial search (+ "Facebook", "Twitter", "Instagram"). We reviewed the first 10 results for any social media presence of the surgeon to simulate what a patient might view. It should be noted that if a physician did have a social media account but it was hidden/private then it would not be accessible to our team. Similarly, it would not be accessible to a potential patient. Therefore, even if a private account was suspected, it was not included because this privacy would deter interacting with patients, and so the account should not be included for the purposes of this study.

\section{Statistical Analysis}

The number of physicians in each city is reported (Table 1). Frequencies and proportions of categorical physician demographics, training, and online presence are reported. Means and standard deviations are reported for continuous variables. To test for differences reported in Table 2 variables based on social media presence, training, practice, and graduation year, Wald chi-square tests were calculated for categorical variables and one-way ANOVA tests were calculated for continuous variables. Social media presence was defined as an online presence on at least one of the following: Facebook, Twitter, or Instagram. The main outcomes of this study include overall rating scores of Healthgrades, Vitals, and Google physician rating websites. The relationship between physician demographics, training, online presence, and that of online reviews (Healthgrades, Vitals, and Google) was assessed with absolute differences and $95 \%$ confidence intervals using bivariate and multivariable linear regression analysis. Variables with a p value $<0.05$ from the bivariate analysis were included in the multivariable model.

Pearson correlation coefficients were calculated and scatterplots generated to evaluate agreement between Healthgrades, Vitals, and Google overall rating scores. A 
correlation coefficient magnitude of 0 to 0.3 was considered to be negligible, 0.3 to 0.5 low, 0.5 to 0.7 moderate, 0.7 to 0.9 high, and 0.9 to 1.0 very high..$^{10} \mathrm{~A} p$ value $<0.05$ was considered to be statistically significant in all calculations. All statistical analysis was performed using SAS 9.4 (SAS Institute Inc.).

\section{Results}

A total of 299 spine surgeons were included in the study. The surgeons' average age was 53.8 years and $95.3 \%$ of the cohort had MD degrees. The majority were trained in orthopedics (64.2\% orthopedic, $35.8 \%$ neurosurgery) and currently work in private practice $(78.5 \%$ private, $21.5 \%$ academic). More than half of the cohort graduated before the year $2000(54.5 \%)$, while $45.5 \%$ graduated in or after 2000 . Nearly all physicians had a personal or institutional website $(90.3 \%)$. At least 1 publicly accessible social media account was record in $43.5 \%$ of our studied spine surgeons $(39.5 \%$ Facebook, $10.4 \%$ Twitter, $2.7 \%$ Instagram). The patient-reported wait times were: $0-10 \mathrm{~min}-$ utes for $11.2 \%, 10-15$ minutes for $42.2 \%, 16-30$ minutes for $38.7 \%$, and $30+$ minutes for $8.0 \%$. The average number of ratings and comments per surgeon was 28.0 and 6.22 for Healthgrades, 34.9 and 11.8 for Vitals, and 6.8 and 5.5 for Google, respectively. The average overall rating per surgeon was 3.9 for Healthgrades, 4.1 for Vitals, and 4.1 for Google (Table 2 and Table 3).

The city with the highest number of spine surgeons was Houston (39), followed by San Antonio (38), Dallas (33), Austin (18), Fort Worth (18), and Plano (18). These 6 cities accounted for $54.8 \%$ of our cohort. Cities with 1 NASSregistered spine surgeon accounted for $42.2 \%$ of all cities with a spine surgeon in Texas (Table 1).

\section{Physician Demographics, Online Presence, and Rating Scores by Social Media Presence, Training, and Practice Setting}

Spine surgeons with a social media presence had a significantly higher number of comments on Healthgrades compared to those without a social media presence (mean 7.5 vs. $5.2, \mathrm{p}=0.01$ ). They were also more likely to have a personal or institutional website $(\mathrm{p}<0.0001)$ and a customized care philosophy listed on their Healthgrades website $(\mathrm{p}=0.02)$. Surgeons with a social media presence were more likely to have graduated recently (after 2000) compared to those without a social media presence $(\mathrm{p}=$ 0.04). Age, $\mathrm{MD} / \mathrm{DO}$ degree, training, practice type, wait times, Castle Connolly status (Vitals), number of comments on Vitals and Google, number of ratings on Healthgrades/Vitals/Google, and overall rating on Healthgrades/ Vitals/Google were not significantly associated with a physician's social media presence (Tables 2 and 3).

Neurosurgery-trained surgeons had a higher overall rating on Vitals compared to orthopedic surgeons $(p=0.04)$. Orthopedic surgeons were more likely to have a social media account on Twitter compared to neurosurgeons ( $\mathrm{p}=$ $0.02)$. Age, $\mathrm{MD} / \mathrm{DO}$ degree, training, practice type, graduation year, wait times, social media presence on Facebook or Instagram, Castle Connolly status (Vitals), listing of a care philosophy (Healthgrades), number of comments and
TABLE 1. Number of spine surgeons in each city

\begin{tabular}{|c|c|}
\hline City & No. of Spine Surgeons \\
\hline Houston & 39 \\
\hline San Antonio & 38 \\
\hline Dallas & 33 \\
\hline Austin & 18 \\
\hline Fort Worth & 18 \\
\hline Plano & 18 \\
\hline El Paso & 11 \\
\hline Tyler & 8 \\
\hline Arlington & 7 \\
\hline Amarillo & 5 \\
\hline Lubbock & 5 \\
\hline The Woodlands & 5 \\
\hline Addison & 4 \\
\hline Beaumont & 4 \\
\hline McAllen & 4 \\
\hline Odessa & 4 \\
\hline Bellaire & 3 \\
\hline Flower Mound & 3 \\
\hline Hurst & 3 \\
\hline Irving & 3 \\
\hline Round Rock & 3 \\
\hline Southlake & 3 \\
\hline Sugar Land & 3 \\
\hline Temple & 3 \\
\hline Allen & 2 \\
\hline Corpus Christi & 2 \\
\hline Denton & 2 \\
\hline Frisco & 2 \\
\hline Grapevine & 2 \\
\hline Lewisville & 2 \\
\hline Longview & 2 \\
\hline Mansfield & 2 \\
\hline McKinney & 2 \\
\hline San Angelo & 2 \\
\hline Shenandoah & 2 \\
\hline Sherman & 2 \\
\hline Wichita Falls & 2 \\
\hline Abilene & 1 \\
\hline Baytown & 1 \\
\hline Bedford & 1 \\
\hline Burleson & 1 \\
\hline Carrollton & 1 \\
\hline College Station & 1 \\
\hline Conroe & 1 \\
\hline Edinburg & 1 \\
\hline Ford Hood & 1 \\
\hline Galveston & 1 \\
\hline Garland & 1 \\
\hline Georgetown & 1 \\
\hline
\end{tabular}

CONTINUED ON PAGE 282 » 
» CONTINUED FROM PAGE 281

TABLE 1. Number of spine surgeons in each city

\begin{tabular}{lc}
\hline \multicolumn{1}{c}{ City } & No. of Spine Surgeons \\
\hline Granbury & 1 \\
\hline JBSA Fort Sam Houston & 1 \\
\hline Katy & 1 \\
\hline Pasadena & 1 \\
\hline Port Arthur & 1 \\
\hline Richardson & 1 \\
\hline Richmond & 1 \\
\hline Rockwall & 1 \\
\hline San Marcos & 1 \\
\hline Shavano Park & 1 \\
\hline Spring & 1 \\
\hline Tomball & 1 \\
\hline Waco & 1 \\
\hline Webster & 1 \\
\hline West Lake Hills & 1 \\
\hline
\end{tabular}

Total: 299 surgeons. Surgeons' practice addresses were obtained from the North American Spine Society membership directory.

ratings, and overall rating on Healthgrades and Google were not significantly associated with the residency training type (Tables 2 and 3).

Spine surgeons in private practice were on average older (mean 55 vs 51 years, $p=0.03$ ) and graduated more recently $(\mathrm{p}=0.02)$ compared to physicians in academic practice. Those in private practice were also more likely to have a social media presence on Facebook compared to academic physicians ( $83 \%$ vs $16 \%, \mathrm{p}=0.04$ ). Private practice physicians had a significantly higher number of reviews and comments on Healthgrades (mean 39 vs 17, $\mathrm{p}=0.0001$ ), but a lower overall rating (mean 3.8 vs 4.1, $\mathrm{p}=0.05)$. They were also more likely to have longer wait times compared to academic physicians $(p=0.003)$. Surgeons in private practice had a higher frequency of ratings on Google $(p=0.04)$ and Vitals $(p=0.005)$ and a higher number of comments on Vitals (mean 13 vs $8, p=0.03$ ). MD/DO degree, training, website, Twitter and Instagram social media, Castle Connolly status (Vitals), listing a care philosophy (Healthgrades), and overall rating on Healthgrades/Vitals/Google was not significantly associated with practice type (Tables 2 and 3).

Physicians graduating in or after the year 2000 had a higher overall rating on Healthgrades (3.7 vs 4.2, p < 0.0001 ), Vitals (3.9 vs $4.3, p=0.002$ ), and Google (3.9 vs $4.2, p=0.01$ ), and a higher number of comments on Healthgrades $(\mathrm{p}<0.0001)$ compared to physicians who graduated before the year 2000. The more recent graduates were more likely to be working in an academic setting $(\mathrm{p}=0.02)$, list a care philosophy (Healthgrades) $(\mathrm{p}$ $=0.01$ ), and have a social media presence on Facebook $(\mathrm{p}=0.01)$, as well as more likely to have a social media presence of any type $(p=0.04)$. Surgeons who graduated prior to 2000 had a shorter average wait time than surgeons who graduated more recently $(\mathrm{p}=0.004)$. MD/DO degree, training, website, social media presence on Twitter and Instagram, Castle Connolly status (Vitals), number of comments on Vitals and Google, and number of ratings on Healthgrades/Vitals/Google were not significantly associated with the year of graduation (Tables 2 and 3).

\section{Bivariate and Multivariable Linear Regression of Healthgrades, Vitals, and Google Overall Scores}

Linear regression models were constructed with overall ratings (on Healthgrades, Vitals, and Google) as the outcome measures (Tables 4 and 5). In both bivariate and multivariable analysis, older surgeons had a significantly lower overall rating across all 3 sites $(\mathrm{p}<0.05)$. For example, on Healthgrades and Vitals, age correlated with a -0.02 in overall score, and so for every 10 -year increase in age there is a 0.2-point decrease in overall rating. A greater number of comments on Healthgrades was associated with a higher overall rating across Healthgrades, Vitals, and Google in bivariate analysis $(\mathrm{p}<0.05)$ but was not found to be significant in the multivariable model. A higher number of ratings on Healthgrades was also associated with a higher Healthgrades overall rating only in bivariate analysis $(p=0.01)$. Longer patient wait time was significantly associated with a lower overall rating on Healthgrades in both bivariate and multivariable analysis $(\mathrm{p}<0.0001)$.

Spine surgeons who completed a neurosurgery residency had higher overall ratings on Vitals compared to orthopedic surgeons in bivariate and multivariable analysis $(\mathrm{p}=0.04)$. On bivariate analysis, spine surgeons who graduated after the year 2000 had a significantly higher overall rating across all 3 sites compared to physicians who graduated before 2000 ( $\mathrm{p}<0.001$ ), but the relationship was not found to be significant in multivariable analysis. Compared to physicians with no website, physicians with a personal or institutional website had higher overall scores on all 3 review sites in bivariate analysis $(p<0.05)$, yet this significance was only maintained by Healthgrades $(\mathrm{p}<0.01)$ in multivariate analysis.

$\mathrm{MD} / \mathrm{DO}$ degree, practice type, social media presence (Facebook/Twitter/Instagram), number of ratings and comments on Google, number of ratings and comments on Vitals, and Castle Connolly status (Vitals) were not significantly associated with overall ratings on Healthgrades, Vitals, or Google and were not included in the multivariable model for analysis.

\section{Healthgrades, Vitals, and Google Correlations}

The 3 online physician rating websites had a significant positive correlation with one another on overall rating scores (Fig. 1). Healthgrades had a weak positive correlation with Vitals overall rating $(\mathrm{r}=0.34$; $95 \%$ CI $0.23-0.44$; $\mathrm{p}<0.0001)$. Healthgrades had a weak positive correlation with Google overall rating $(\mathrm{r}=0.37$; 95\% CI $0.24-0.47$; $\mathrm{p}$ $<0.0001)$. Vitals had a negligible positive correlation with Google overall rating $(\mathrm{r}=0.15 ; 95 \%$ CI $0.02-0.28 ; \mathrm{p}=0.03)$.

\section{Discussion}

It is most likely that surgeons' online scores are influenced by a combination of factors, such as clinical outcomes, physician character/likability, office staff, and billing. Physician availability and personality are less tangible 


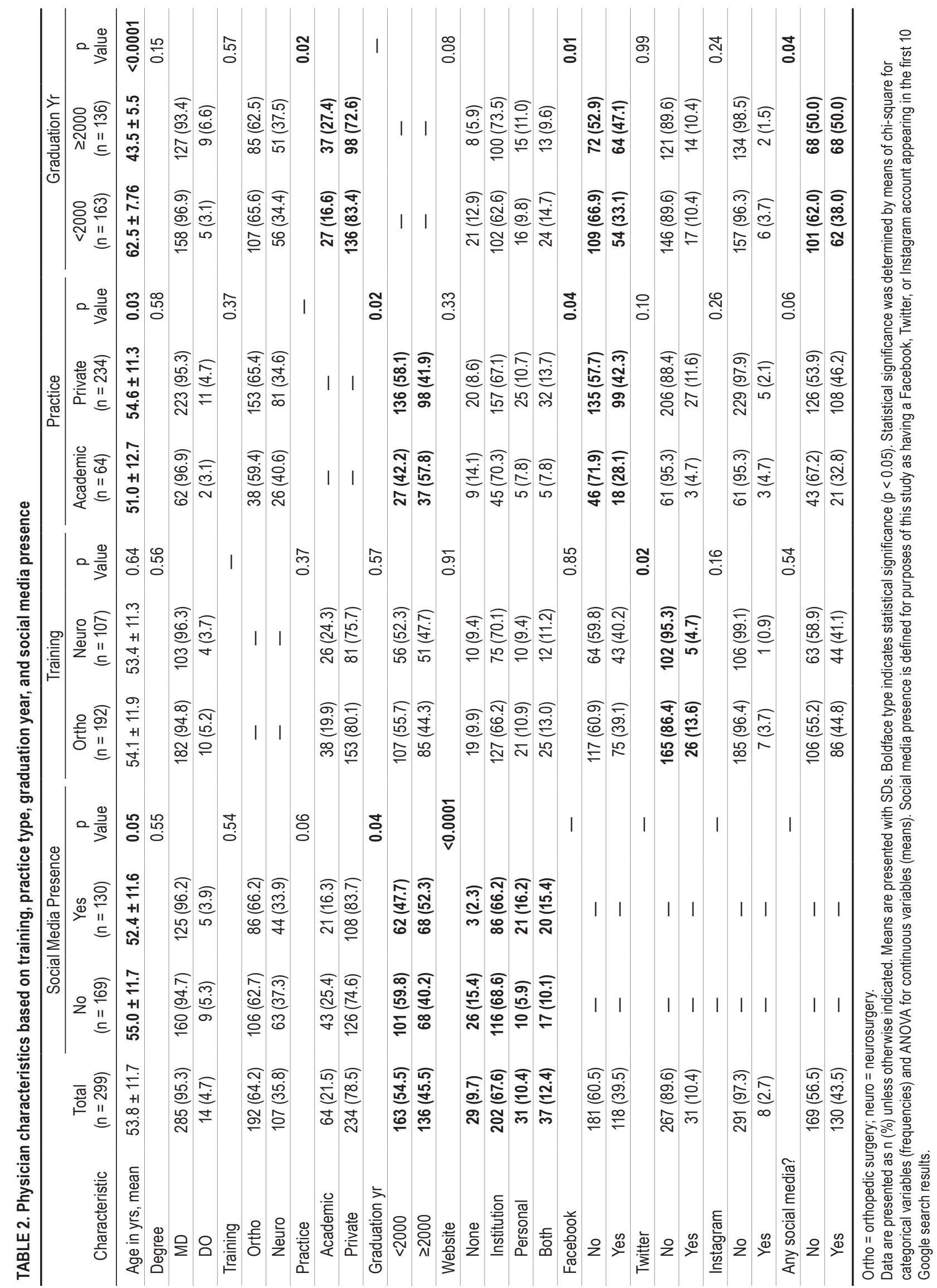




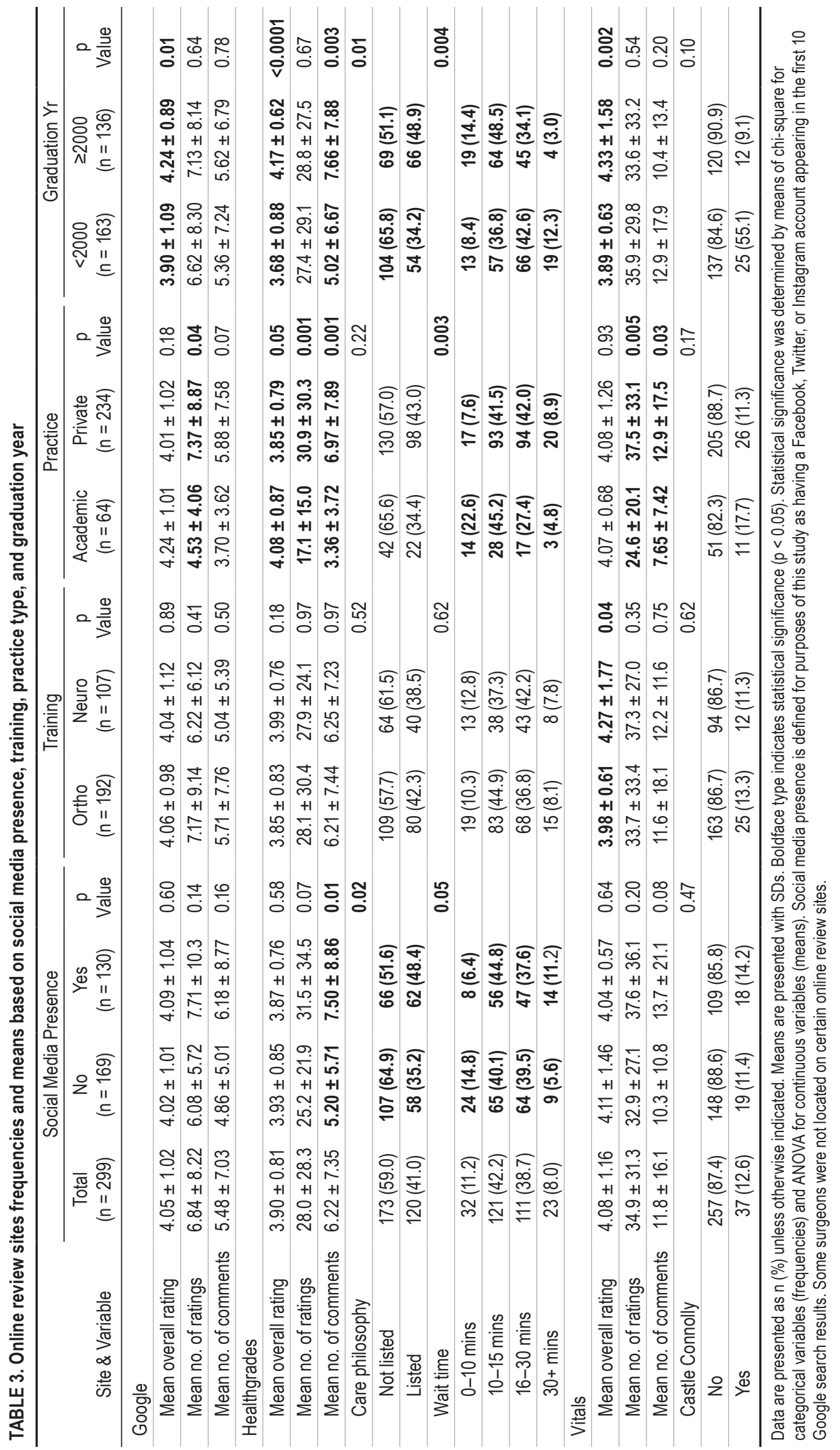


TABLE 4. Bivariate linear regression of Healthgrades, Vitals, and Google overall ratings

\begin{tabular}{|c|c|c|c|c|c|c|}
\hline \multirow[b]{2}{*}{ Variable } & \multicolumn{2}{|c|}{ Healthgrades Overall Rating } & \multicolumn{2}{|c|}{ Vitals Overall Rating } & \multicolumn{2}{|c|}{ Google Overall Rating } \\
\hline & $\mathrm{AD}(95 \% \mathrm{Cl})$ & p Value & $\mathrm{AD}(95 \% \mathrm{Cl})$ & $p$ Value & $\mathrm{AD}(95 \% \mathrm{Cl})$ & $\mathrm{p}$ Value \\
\hline Age & $-0.03(-0.04$ to -0.02$)$ & $<0.0001$ & $-0.03(-0.04$ to -0.01$)$ & $<0.0001$ & $-0.02(-0.03$ to -0.01$)$ & 0.0004 \\
\hline \multicolumn{7}{|l|}{ Degree } \\
\hline MD & 0 & & 0 & & 0 & \\
\hline DO & $0.01(-0.42$ to 0.45$)$ & 0.95 & $-0.05(-0.70$ to 0.59$)$ & 0.87 & $-0.04(-0.65$ to 0.58$)$ & 0.91 \\
\hline \multicolumn{7}{|l|}{ Training } \\
\hline Ortho & 0 & & 0 & & 0 & \\
\hline Neuro & $0.14(-0.07$ to 0.34$)$ & 0.17 & $0.29(0.01$ to 0.57$)$ & 0.04 & $-0.02(-0.30$ to 0.26$)$ & 0.89 \\
\hline \multicolumn{7}{|l|}{ Practice } \\
\hline Academic & 0 & & 0 & & 0 & \\
\hline Private & $-0.23(-0.46$ to 0$)$ & 0.05 & $0.02(-0.03$ to 0.35$)$ & 0.93 & $-0.23(-0.57$ to 0.11$)$ & 0.18 \\
\hline \multicolumn{7}{|l|}{ Graduation yr } \\
\hline$<2000$ & 0 & & 0 & & 0 & \\
\hline$\geq 2000$ & $0.49(0.31-0.67)$ & $<0.0001$ & $0.43(0.17-0.70)$ & 0.001 & $0.34(0.08-0.61)$ & 0.01 \\
\hline \multicolumn{7}{|l|}{ Website } \\
\hline None & 0 & & 0 & & 0 & \\
\hline Institution & $0.73(0.39-1.08)$ & $<0.0001$ & $0.45(-0.01$ to 0.92$)$ & 0.05 & $0.76(0.19-1.33)$ & 0.009 \\
\hline Personal & $0.60(0.16-1.03)$ & 0.007 & $0.36(-0.24$ to 0.96$)$ & 0.24 & $0.84(0.17-1.50)$ & 0.01 \\
\hline Both & $0.53(0.12-0.95)$ & 0.01 & $0.36(-0.22$ to 0.94$)$ & 0.22 & $0.72(0.07-1.37)$ & 0.03 \\
\hline \multicolumn{7}{|l|}{ Facebook } \\
\hline No & 0 & & 0 & & 0 & \\
\hline Yes & $-0.02(-0.22$ to 0.17$)$ & 0.81 & $-0.02(-0.30$ to 0.25$)$ & 0.87 & $0.04(-0.23$ to 0.31$)$ & 0.76 \\
\hline \multicolumn{7}{|l|}{ Twitter } \\
\hline No & 0 & & 0 & & 0 & \\
\hline Yes & $-0.03(-0.33$ to 0.28$)$ & 0.86 & $-0.17(-0.60$ to 0.26$)$ & 0.44 & $-0.24(-0.65$ to 0.17$)$ & 0.25 \\
\hline \multicolumn{7}{|l|}{ Instagram } \\
\hline No & 0 & & 0 & & 0 & \\
\hline Yes & $0.32(-0.25$ to 0.89$)$ & 0.27 & $0.10(-0.71$ to 0.92$)$ & 0.80 & $0.02(-0.70$ to 0.75$)$ & 0.95 \\
\hline \multicolumn{7}{|l|}{ Any social media } \\
\hline No & 0 & & 0 & & 0 & \\
\hline Yes & $-0.05(-0.24$ to 0.14$)$ & 0.58 & $-0.07(-0.34$ to 0.21$)$ & 0.64 & $0.07(-0.20$ to 0.34$)$ & 0.60 \\
\hline \multicolumn{7}{|l|}{ Google } \\
\hline No. of ratings & $0.01(0-0.02)$ & 0.13 & $0.01(-0.02$ to 0.03$)$ & 0.63 & $0.005(-0.01$ to 0.02$)$ & 0.57 \\
\hline No. of comments & $0.01(0-0.02)$ & 0.16 & $0.01(-0.02$ to 0.03$)$ & 0.58 & $0.004(-0.01$ to 0.02$)$ & 0.65 \\
\hline \multicolumn{7}{|l|}{ Healthgrades } \\
\hline No. of ratings & $0.004(0-0.01)$ & 0.01 & $0.002(-0.003$ to 0.01$)$ & 0.50 & $0.001(-0.003$ to 0.01$)$ & 0.64 \\
\hline No. of comments & $0.03(0.01-0.04)$ & $<0.0001$ & $0.03(0.01-0.05)$ & 0.002 & $0.02(0-0.03)$ & 0.04 \\
\hline \multicolumn{7}{|l|}{ Care philosophy } \\
\hline Not listed & 0 & & 0 & & 0 & \\
\hline Listed & $0.33(0.14-0.52)$ & 0.0005 & $0.09(-0.18$ to 0.36$)$ & 0.53 & $0.25(-0.02$ to 0.51$)$ & 0.07 \\
\hline \multicolumn{7}{|l|}{ Wait time } \\
\hline $0-10$ mins & 0 & & 0 & & 0 & \\
\hline $10-15$ mins & $-0.62(-0.94$ to -0.31$)$ & 0.0001 & $-0.20(-0.69$ to 0.29$)$ & 0.43 & $-0.07(-0.65$ to 0.50$)$ & 0.80 \\
\hline $16-30$ mins & $-1.16(-1.48$ to -0.84$)$ & $<0.0001$ & $-0.17(-0.67$ to 0.32$)$ & 0.49 & $-0.17(-0.74$ to 0.41$)$ & 0.57 \\
\hline $31+\operatorname{mins}$ & $-1.47(-1.88$ to -1.06$)$ & $<0.0001$ & $-0.56(-1.21$ to 0.09$)$ & 0.09 & $-0.33(-1.06$ to 0.39$)$ & 0.37 \\
\hline \multicolumn{7}{|l|}{ Vitals } \\
\hline No. of ratings & $0.002(-0.001$ to 0.005$)$ & 0.31 & $-0.001(-0.01$ to 0.003$)$ & 0.57 & $0.0001(-0.004$ to 0.004$)$ & 0.97 \\
\hline No. of comments & $0.004(0-0.01)$ & 0.21 & $-0.001(-0.01$ to 0.01$)$ & 0.90 & $0.001(-0.007$ to 0.009$)$ & 0.77 \\
\hline
\end{tabular}


» CONTINUED FROM PAGE 285

TABLE 4. Bivariate linear regression of Healthgrades, Vitals, and Google overall ratings

\begin{tabular}{|c|c|c|c|c|c|c|}
\hline \multirow[b]{2}{*}{ Variable } & \multicolumn{2}{|c|}{ Healthgrades Overall Rating } & \multicolumn{2}{|c|}{ Vitals Overall Rating } & \multicolumn{2}{|c|}{ Google Overall Rating } \\
\hline & $\mathrm{AD}(95 \% \mathrm{Cl})$ & p Value & $\mathrm{AD}(95 \% \mathrm{Cl})$ & p Value & $\mathrm{AD}(95 \% \mathrm{Cl})$ & $\mathrm{p}$ Value \\
\hline \multicolumn{7}{|c|}{ Vitals (continued) } \\
\hline \multicolumn{7}{|c|}{ Castle Connolly } \\
\hline No & 0 & & 0 & & 0 & \\
\hline Yes & $-0.03(-0.31$ to 0.25$)$ & 0.82 & $-0.04(-0.44$ to 0.37$)$ & 0.86 & $0.10(-0.29$ to 0.48$)$ & 0.62 \\
\hline
\end{tabular}

$A D=$ absolute difference.

Social media presence defined as having a Facebook, Twitter, or Instagram account located in the first 10 Google search results; boldface type indicates statistical significance $(p<0.05)$.

factors that patients admire. While maybe seeming trivial 10 years ago, social media are just as deeply incorporated into the professional world as corporate websites, and social media outreach helps organizations and providers communicate and interact with clients. We found that those with social media were also more likely to have a personal website than those without social media. This correlation might indicate that those attempting to market themselves using a personal website would also be the surgeons using social media as a marketing platform.

Interestingly, we noted an increase in the number of total comments on Healthgrades for those physicians with social media accounts. It is possible that surgeons using social media to interact with patients are also the same ones asking patients to share their experiences online compared to those without social media. These physicians were also more likely to have personalized their Healthgrades accounts with a "care philosophy" giving insight into what drives their practice. These findings indicate that physicians with social media accounts are more "cyber" engaged with their patients, a trait that needs future study. Even so, presence (or absence) of a public social media account did not affect the overall physician rating on any of the review sites studied. This may indicate that the reviews

TABLE 5. Multivariable linear regression of Healthgrades, Vitals, and Google overall ratings

\begin{tabular}{|c|c|c|c|c|c|c|}
\hline \multirow[b]{2}{*}{ Variable } & \multicolumn{2}{|c|}{ Healthgrades Overall Rating } & \multicolumn{2}{|c|}{ Vitals Overall Rating } & \multicolumn{2}{|c|}{ Google Overall Rating } \\
\hline & $\mathrm{AD}(95 \% \mathrm{Cl})$ & $p$ Value & $\mathrm{AD}(95 \% \mathrm{Cl})$ & $p$ Value & $\mathrm{AD}(95 \% \mathrm{Cl})$ & $\mathrm{p}$ Value \\
\hline Age & $-0.02(0.03$ to -0.01$)$ & 0.004 & $-0.03(-0.05$ to -0.01$)$ & 0.008 & $-0.02(-0.04$ to -0.001$)$ & 0.04 \\
\hline \multicolumn{7}{|l|}{ Training } \\
\hline Ortho & - & & 0 & & - & \\
\hline Neuro & - & - & $0.30(0.02-0.58)$ & 0.04 & - & - \\
\hline \multicolumn{7}{|l|}{ Graduation yr } \\
\hline$<2000$ & 0 & & 0 & & 0 & \\
\hline$\geq 2000$ & $-0.05(-0.31$ to 0.21$)$ & 0.70 & $-0.12(-0.57$ to 0.33$)$ & 0.60 & $-0.09(-0.53$ to 0.35$)$ & 0.69 \\
\hline \multicolumn{7}{|l|}{ Website } \\
\hline None & 0 & & - & & 0 & \\
\hline Institution & $0.61(0.31-0.91)$ & $<0.0001$ & - & - & $0.49(-0.10$ to 1.07$)$ & 0.10 \\
\hline Personal & $0.46(0.09-0.84)$ & 0.01 & - & - & $0.59(-0.09$ to 1.27$)$ & 0.09 \\
\hline Both & $0.46(0.09-0.82)$ & 0.01 & - & - & $0.45(-0.21$ to 1.11$)$ & 0.18 \\
\hline \multicolumn{7}{|l|}{ Healthgrades } \\
\hline No. of ratings & $-0.001(-0.01$ to 0.003$)$ & 0.80 & - & - & - & - \\
\hline No. of comments & $0.01(-0.01$ to 0.03$)$ & 0.17 & $0.02(0-0.04)$ & 0.06 & $0.01(-0.01$ to 0.02$)$ & 0.48 \\
\hline \multicolumn{7}{|l|}{ Care philosophy } \\
\hline Not listed & 0 & & - & - & - & - \\
\hline Listed & $0.08(-0.09$ to 0.25$)$ & 0.35 & - & - & - & - \\
\hline Wait time & & & - & - & - & - \\
\hline $0-10$ mins & 0 & - & - & - & - & - \\
\hline $10-15$ mins & $-0.74(-1.03$ to -0.45$)$ & $<0.0001$ & - & - & - & - \\
\hline $16-30$ mins & $-1.18(-1.47$ to -0.89$)$ & $<0.0001$ & - & - & - & - \\
\hline $31+$ mins & $-1.34(-1.72$ to -0.96$)$ & $<0.0001$ & - & - & - & - \\
\hline
\end{tabular}

Boldface type indicates statistical significance $(p<0.05)$. 
on these sites are based on physician ability and personality and less on marketing outreach.

Another effective way to market oneself online is through the use of a personal or institutional website. Websites allow physicians to tailor what information a prospective patient sees and better advertise their skill set as to what conditions they typically manage. In a bivariate model, we found that being easily accessible on your institutional website was correlated with an increase in all 3 physician review site ratings. These findings held true in a multivariate model for Healthgrades. It may be that patients are better able to find a physician who fits their needs when searching online, leading to higher ratings for these physicians.

Our group also investigated the effect of physician age on patient reviews online. Curry et al. found that $51 \%$ of orthopedic patients use social media, and of those who do not, $92 \%$ were above the age of $40 .{ }^{3}$ Another study of Internet review trends for surgeons reported that those who have been in practice for less than 10 years were reviewed more often than those who have been in practice longer. ${ }^{9}$ In our study, we found this correlation to hold true on Healthgrades, but it was statistically insignificant for the other 2 review sites. To separate our cohort based on experience, we compared those who graduated from residency before the year 2000 with those graduating during or after 2000 . Interestingly, those in the prior-to-2000 cohort on average had lower overall ratings across all 3 review sites as well as longer wait times in a bivariate model $(\mathrm{p}<0.05)$, but this significance was lost in multivariate analysis. One potential explanation of favorable ratings associated with more recent graduates is the encouragement of those with favorable outcomes to leave a review online to further boost the physician's appearance.

A "care philosophy" is a way for physicians to personalize their Healthgrades page and potentially target a specific patient population. Younger physicians were more likely than older physicians to post a "care philosophy" on Healthgrades, again showing a likely desire to interact with their patients and indirectly help market their young career. In a bivariate model, having a posted care philosophy is associated with an increased Healthgrades score. It is unclear whether the posted care philosophy has any impact on patients selecting a care provider, but it can be argued that this customization may influence a patient to later leave a rating, knowing that the surgeon has similarly valued this review site.

The single most predictive factor for the surgeons' overall rating on Healthgrades was patient-reported wait times, with longer times being associated with worse scores. Similar studies evaluating physician online reviews found similar results of increasing wait time correlating with a decreasing online rating.,12,15 Trehan et al. found that negative reviews are more likely to be caused by surgeon-independent factors, while positive reviews were more likely to be due to the surgeon's ability. ${ }^{14}$ Factors such as wait time, staff friendliness, and office environment are important to maintain in order to avoid poor reviews online. Of course the surgeon's clinic wait time likely has little correlation with his or her outcomes, which should really be the driver of online scores. Even so, decreasing patient wait times
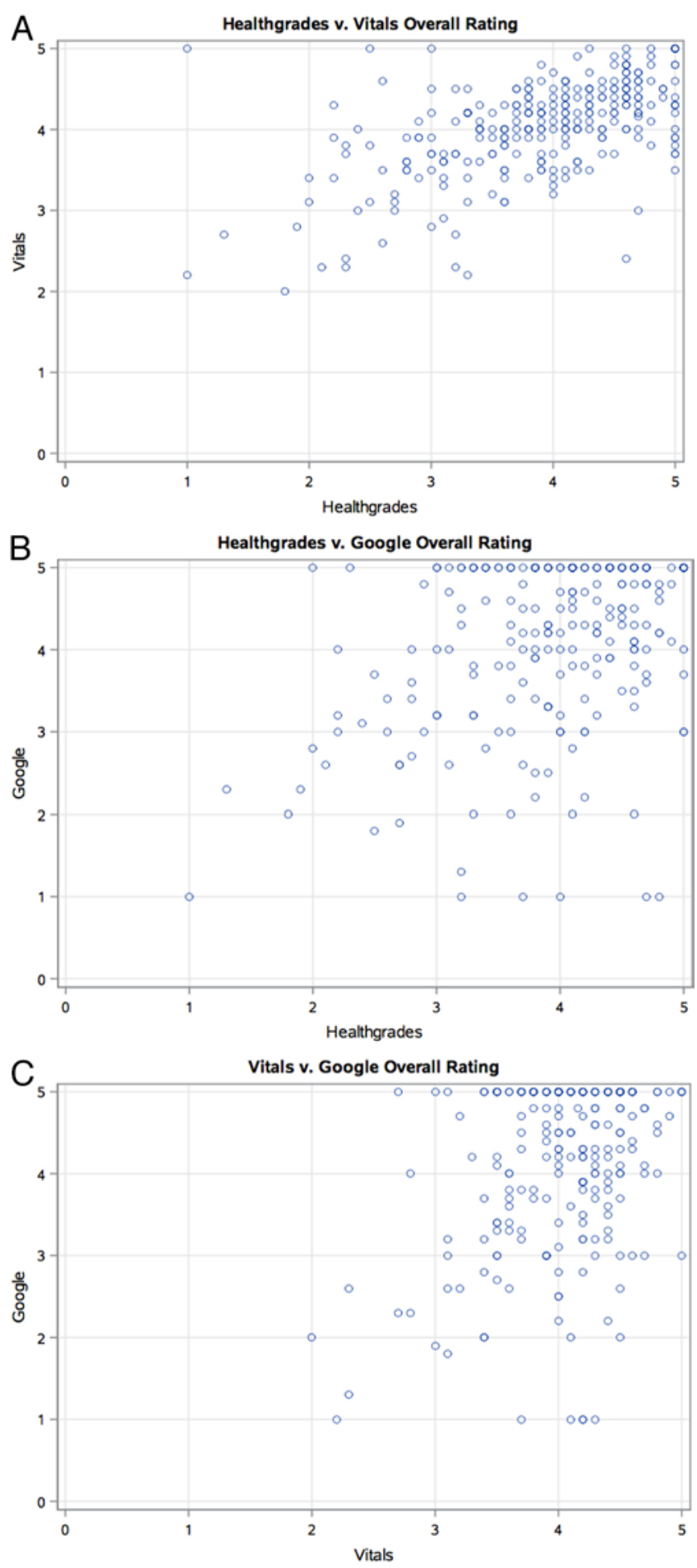

FIG. 1. Pearson correlation scatterplots. A: Healthgrades versus Vitals $(r=0.34,95 \% \mathrm{Cl} 0.23-0.44, p<0.0001)$. B: Healthgrades versus Google $(r=0.37,95 \% \mathrm{Cl} 0.24-0.47, p<0.0001)$. C: Vitals versus Google $(r=0.15,95 \% \mathrm{Cl} 0.02-0.28, p=0.03) . v=$ versus. Figure is available in color online only.

should be a priority for any physician, as it may negatively affect one's perception online. Other studies should further evaluate the impact of comment types and reported outcomes with online scores. ${ }^{4}$ 
The ratings on Healthgrades, Vitals, and Google were all found to be significantly positively correlated. To date, our group is the first to compare ratings for both neurosurgeon and orthopedic surgeons practicing on the spine on all 3 of these websites. The general agreement of physician ratings across these 3 separate platforms lends validity to our findings and generalizability to our results across these 3 websites.

One of the limitations of our study is that the results may not be applicable to spine surgeons in other geographic regions. We also reviewed only spine surgeons who had registered with NASS and reported their practice to be in our studied region. We therefore relied on surgeons updating their profile with current practice locations. Those who registered many years prior and have not yet updated their profile since moving into our studied region were not included. We also cannot confirm that the patients were even aware of a surgeon's social media account, but would argue that surgeons with a public social media are probably also promoting their practice in additional ways not fully captured in this review. Additionally, while we chose the review websites based on these three being seen as very reputable, there are other online review sites that potentially are more indicative of patient engagement and satisfaction. Ratings may also be affected by patient variables such as age and insurance status. ${ }^{7}$ It may also benefit all parties if review sites listed certain demographic parameters about the reviewer. Another limitation is for surgeons with few reviews in that they lack a critical mass at which a fair overall score should be determined. For example, one negative review may skew the overall review for a physician who has few reviews versus one who has many. ${ }^{11}$ It is also unclear if all of the posted reviews were performed by actual patients. It is feasible that competitors or patient family members may maliciously post negative reviews. In subsequent studies one could examine the actual patient reviews collected by insurance agencies, which would verify that the reviews were from treated patients.

\section{Conclusions}

Our study demonstrates that online physician interaction, in the form of Web presence, may have a positive impact on review site scores, and therefore, overall physician perception. At first glance, these results may demonstrate a push toward increased online presence and focus; however, the association between increasing review scores and shorter wait times also reiterates the value of the physical doctor-patient relationship, even in this digital age. A balance between Internet presence and clinic efficiency appears to be crucial in maintaining high patient satisfaction and may be the key to physician success in the ever more digitized medical landscape.

\section{References}

1. Bakhsh W, Mesfin A: Online ratings of orthopedic surgeons: analysis of 2185 reviews. Am J Orthop 43:359-363, 2014

2. Chowdhury A: What are the top doctor rating and review sites? A deep dive into the best sites for healthcare reviews. Doctible. (https://blog.doctible.com/what-are-the-top-doctorrating-and-review-sites-20d32ba1ec81) [Accessed September 4, 2018]
3. Curry E, Li X, Nguyen J, Matzkin E: Prevalence of internet and social media usage in orthopedic surgery. Orthop Rev (Pavia) 6:5483, 2014

4. Donnally CJ III, Roth ES, Li DJ, Maguire JA Jr, McCormick JR, Barker GP, et al: Analysis of internet review site comments for spine surgeons: how office staff, physician likeability, and patient outcome are associated with online evaluations. Spine (Phila Pa 1976) [epub ahead of print], 2018

5. Duymus TM, Karadeniz H, Çaçan MA, Kömür B, Demirtaş A, Zehir S, et al: Internet and social media usage of orthopaedic patients: A questionnaire-based survey. World J Orthop 8:178-186, 2017

6. Duymuş TM, Karadeniz H, Şükür E, Atiç R, Zehir S, Azboy İ: Social media and Internet usage of orthopaedic surgeons. J Clin Orthop Trauma 8:25-30,2017

7. Emmert M, Meier F: An analysis of online evaluations on a physician rating website: evidence from a German public reporting instrument. J Med Internet Res 15:e157, 2013

8. Hanauer DA, Zheng K, Singer DC, Gebremariam A, Davis MM: Public awareness, perception, and use of online physician rating sites. JAMA 311:734-735, 2014

9. Jack RA II, Burn MB, McCulloch PC, Liberman SR, Varner KE, Harris JD: Does experience matter? A meta-analysis of physician rating websites of orthopaedic surgeons. Musculoskelet Surg 102:63-71, 2018

10. Mukaka MM: Statistics corner: A guide to appropriate use of correlation coefficient in medical research. Malawi Med J 24:69-71, 2012

11. Nwachukwu BU, Adjei J, Trehan SK, Chang B, AmooAchampong K, Nguyen JT, et al: Rating a sports medicine surgeon's "quality" in the modern era: an analysis of popular physician online rating websites. HSS J 12:272-277, 2016

12. Obele CC, Duszak R Jr, Hawkins CM, Rosenkrantz AB: What patients think about their interventional radiologists: assessment using a leading physician ratings website. J Am Coll Radiol 14:609-614, 2017

13. Swayne LC: Pay for performance: pay more or pay less? J Am Coll Radiol 2:777-781, 2005

14. Trehan SK, DeFrancesco CJ, Nguyen JT, Charalel RA, Daluiski A: Online patient ratings of hand surgeons. J Hand Surg Am 41:98-103, 2016

15. Vu AF, Espinoza GM, Perry JD, Chundury RV: Online ratings of ASOPRS surgeons: what do your patients really think of you? Ophthal Plast Reconstr Surg 33:466-470, 2017

\section{Disclosures}

Dr. Wang reports consultant relationships with DePuy-Synthes Spine, K2M, Spineology, Globus Medical, and Stryker; a patent holder relationship with DePuy-Synthes Spine; and direct stock ownership in ISD.

\section{Author Contributions}

Conception and design: Donnally, Rush, Wang. Acquisition of data: McCormick, Li, Maguire, Barker. Analysis and interpretation of data: McCormick, Li, Maguire, Barker, Rush. Drafting the article: Donnally, McCormick, Rush. Critically revising the article: Donnally, McCormick, Rush, Wang. Reviewed submitted version of manuscript: all authors. Approved the final version of the manuscript on behalf of all authors: Donnally. Statistical analysis: Donnally. Administrative/technical/material support: Donnally. Study supervision: Donnally, Rush, Wang.

\section{Correspondence}

Chester J. Donnally III: University of Miami Hospital, Miami, FL.chester.donnally@jhsmiami.org. 